\title{
Herbal Cosmetics and Novel Drug Delivery Systems
}

\author{
Evren ALĞIN YAPAR*
}

Associate Professor, Republic of Turkey Ministry of Health, Turkish Medicines and Medical Devices Agency, TURKEY.

\begin{abstract}
Herbal cosmetics are defined as the products which prepared by or included plants and/or herbal components which are combination of many natural molecules or compounds. In this context, critical parameters that affect the final quality and stability of herbal cosmetics are the specifications of herbal inputs, structure of formulation and manufacturing process. In addition to produce according to the good manufacturing practices of cosmetics (ISO 22716) in case of being natural or organic cosmetic it needs to meet the related international standard for technical definitions and criteria of natural and organic cosmetic ingredients and products (ISO 16128). Novel drug delivery systems are used in herbal cosmetics and between them vesicular, particular and emulsion based delivery systems are most preferable delivery systems. The advantages of such systems for herbal cosmetics can be listed as; enhanced efficacy, improved stability and decrease allergic potential of some herbal substances. As a result, choosing an appropriate drug delivery system for a herbal cosmetic is able to provide increased efficacy, stability and enhanced safety of the final product. Besides these advantages above mentioned since herbal cosmetics have become more complicated the fulfillment of quality requirements either during production or after packaging and during shelf life would be critical that need to fulfill long-term stability and dermatological safety.
\end{abstract}

Key words: Herbal cosmetics, Naturel sources, Novel delivery systems, Standards, Stability.

\section{INTRODUCTION}

The cosmetics have been originated from plants in its historical development. Traditional use of plants for cosmetic purposes based on perfuming and skin care in the form of infusions, poultices and etc. In the last century, researchers have been focused on plants to investigate their efficacy and safety in cosmetics field. Generally herbal sources are rich with vitamins, antioxidants, oils (essential etc.) hydrocolloids, proteins, terpenoids and other bioactive compounds which have functions in the scope of cosmetics such as anti-aging, anti-oxidant, emollient effect etc. Herbs can be utilized for cosmetics in different forms as: i. a part of herb, ii. total extract of the herb, iii. extract of selective parts or iv. specific molecules purified from extracts. According to the composition of herbal raw materials herbal cosmetics which contain one or more herbal ingredients present different activities or properties. In the scope of herbal cosmetics phytocosmetics are defined as the products which prepared only by plants and/or herbal components and mainly included; plants, plant extracts, volatile oils, distillates, aromatic waters, juices, aqueous extracts, tinctures, resins, gums and congenerous, herbal oilslipids, waxes, mucilages, plant carbohydrates or purified plant components. Significant activities in case of phytocosmetics are generally; antioxidant activity, antityrosinase activity and antimicrobial activity. As the phytoformulation is a mixture of more than one active ingredient, care should be taken to the determination of the stability profile for phytocosmetics/herbal cosmetics. ${ }^{1-3}$ Quantitative standards of all the herbal components need to determined according to a globally acceptable reference such as
DOI: 10.5530/ijper.51.3s.3 Correspondence: Assoc.Prof. Evren ALĞIN YAPAR*,

Republic of Turkey Ministry of Health, Turkish Medicines and Medical Devices Agency, Sögütözü Mahallesi 2176. Sokak No:5 PK 06520 Çankaya/Ankara, Türkiye. Phone no:+(90) 3122183649 E-mail: evren.yapar@yahoo. com

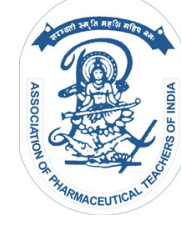

www.ijper.org 
The Ayurvedic Pharmacopoeia of India, Chinese Pharmacopeia and etc. Critical parameters that affect the final quality and stability of herbal cosmetics/phytocosmetics are the specifications of herbal inputs, structure of formulation and manufacturing process. In this context the critical analyses of quality control of herbal raw materials are performed in addition to in-process and the postanalyses of the herbal cosmetics. As a main requirement Cosmetic Good Manufacturing Practices (ISO 22716) need to be adopted to herbal cosmetic/phytocosmetic producing processes. Briefly critical issues can be indicated as follows; i. All components and manufacturing processes required to be standardized and documented. ii. A quality assurance system need to be established. In addition to produce according to the good manufacturing practices of cosmetics in case of being natural or organic cosmetic it needs to meet the related international standards the ISO 16128-1 and ISO 16128-2 which provides guidelines on definitions and criteria for natural and organic cosmetic ingredients and products. ${ }^{47}$ In this direction the controls and analyses that can be carried on herbal raw materials and ingredients can be listed as; i. organoleptic controls, botanical controls, product packaging, lot number, labeling (harvest date), ii. physical controls (resolution, fluorescence analysis, swelling index, foaming index etc.), iii. chemical controls (qualitative identification reactions, quantitative analyses, determination of impurities, bitterness value, the determination of heavy metals, pesticide residue analyses, mycotoxin control, determination of radioactive contamination, etc.), iv. biological controls (microbial contamination control), v. chromatographic and spectroscopic analyses (HPLC, GC, TLC, IR, UV-Spectrometer, etc.). ${ }^{4-9}$ Herbal cosmetic products which are formulated with novel drug delivery systems have presented advanced cosmetic specifications by means of anti-aging, antioxidant, anti-cellulite, anti-hair loss, anti-microbial, anti-blemish, nourishing and moisturizing effects. In cosmetics, the main concern is to reach the cutaneous cells to obtain better topical efficacy. The use of novel drug delivery systems in cosmetics provides capabilities of enhancing cosmetic ingredients to deeper skin tissues, increase the duration of action, increase the stability, eliminate incompatibility with other ingredients in the cosmetic formulations or the prevention of undesirable effects that may occur in the administration site. Encapsulation techniques are most widely used in cosmetics to achieve above mentioned purposes. Among the delivery systems following indicated three groups are generally used for cosmetics. The first group is vesicular systems; liposomes, silicone vesicles and matrices and the multiwalled delivery systems can be accepted the most important group. The second group is the emulsions; microemulsions, liquid crystals, multiple emulsions, nanoemulsions and pickering emulsions can be accepted as the largest group. The third group is the debated particulate systems; microparticles, porus polymeric systems, nanoparticles and cycledextrin complexes. ${ }^{10-14}$ Safety is an important issue especially for complicated cosmetics. Despite it is assumed herbal cosmetics have less adverse effects than the synthetic based ones, the safety evaluation is being decisive for the safety of all cosmetics. In broad perspective plants originated adverse effects and their evaluation is falling under phytopharmacovigilance which searches proper identification of plants, procurement of the raw material, process of extraction, the percentage of the active ingredients and marker compounds, etc. For the irritation potential of herbal cosmetics, in vitro cytotoxic potential of herbal sources could be performed in several human cell lines. Adverse effect is termed as an undesirable effect for cosmetics. With the use of cosmetics under normal or reasonably foreseeable conditions of the spontaneous gathering of undesirable effects observed reporting, evaluation and monitoring activities are expressed as a warning system which called as cosmetovigilance. ${ }^{15-16}$

\section{HERBAL SOURCES}

Cosmetic products can be formulated either for personal cleaning and care or for various advanced purposes such as reducing wrinkles, spots, cellulite and etc. Herbal cosmetics are generally developed for purposes such as moisturizing dry skin, anti-aging effect, reducing wrinkles, skin lightening, removal of dark spots, controlling oil secretion, anti-dandruff effect, skin protection, hair care and anti-oxidative antipollution effects. In some cases and requirements, only specific functional active ingredients can achieve mentioned purposes effectively. These specific functional active ingredients can be accepted as common cosmeceutical ingredients such as; hydroxy acids (alpha hydroxy acids /AHAs: citric acid, malic acid, glycolic acid, lactic acid, pyruvic acid, tartaric acid, lactobionic acid,and beta hydroxy acids/ BHAs: salicylic acid referred as fruit acids), antioxidants (alpha-lipoic acid/ALA, L-ascorbic acid/ vitamin C, niacinamide/vitamin $\mathrm{B} 3, \mathrm{~N}$-acetyl glucosamine/NAG, $\alpha$-Tocopherol and ubiquinone/CoQ10), botanicals (grape seed extract and ferulic acid), depigmenting agents (hydroquinone, ascorbic acid/vitamin C, kojic acid and liquorice extract), retinoids (retinoic acid/ tretinoin, retinol and retinaldehyde), hyaluronic acid and ceramides. ${ }^{10,17-19} \mathrm{In}$ addition to their positive effects on the skin, herbal sources also can be used as an alternative 


\begin{tabular}{|c|c|c|c|c|}
\hline Species & Used parts & Active components & Benefits & Product forms \\
\hline Cocos nucifera & Oil, Fruits, seeds & Fatty acids & $\begin{array}{l}\text { Useful for itching and } \\
\text { rashes, Moisturizing, } \\
\text { Softening }\end{array}$ & $\begin{array}{l}\text { Bath products, eye makeup, hair care } \\
\text { products, shaving creams, suntan } \\
\text { products, skin care products and } \\
\text { lipsticks. }\end{array}$ \\
\hline $\begin{array}{l}\text { Helianthus } \\
\text { annuus }\end{array}$ & $\begin{array}{l}\text { Oil, Flowers, } \\
\text { Leaves, Seeds, }\end{array}$ & $\begin{array}{l}\text { Lecithin, } \\
\text { tocopherols, } \\
\text { carotenoids, waxes }\end{array}$ & Smoothing & $\begin{array}{l}\text { Hair care products, skin care products, } \\
\text { creams }\end{array}$ \\
\hline Aloe vera & Leaves & $\begin{array}{l}\text { Glucomannans, } \\
\text { Anthraquinones, } \\
\text { lignins }\end{array}$ & $\begin{array}{l}\text { Moisturizing, Softening, } \\
\text { Useful for healing, } \\
\text { UV protection }\end{array}$ & $\begin{array}{l}\text { Bath products, shaving creams, skin } \\
\text { care products and lipsticks. } \\
\text { Lotion, cream }\end{array}$ \\
\hline Rhodiola rosea & Golden root & $\begin{array}{l}\text { Flavanoids, } \\
\text { Monoterpernes, } \\
\text { Triterpernes, } \\
\text { Phenolic acids }\end{array}$ & $\begin{array}{l}\text { Antioxidant, } \\
\text { Moisturizing }\end{array}$ & Skin care products \\
\hline Daucus carota & $\begin{array}{l}\text { Fruits, seeds, } \\
\text { flowers, leaves, } \\
\text { roots }\end{array}$ & Vitamin A & $\begin{array}{l}\text { Anti-Aging, Revitalizing, } \\
\text { Rejuvenating } \\
\text { Smoothing }\end{array}$ & Skin care products \\
\hline Ginkgo biloba & Leaves, roots & Terpenoids & Antioxidant, tonic & Hair care products, skin care products, \\
\hline Lawsonia inermis & Leaves, flowers & $\begin{array}{l}\text { Lawsone (a dye } \\
\text { molecule) }\end{array}$ & $\begin{array}{l}\text { Hair coloring and } \\
\text { nourishment }\end{array}$ & Hair care products, \\
\hline $\begin{array}{l}\text { Azadirachta } \\
\text { indica }\end{array}$ & $\begin{array}{l}\text { Leaves, Seeds, } \\
\text { Barks }\end{array}$ & $\begin{array}{l}\text { Nimbin, } \\
\text { Nimbinin }\end{array}$ & $\begin{array}{l}\text { Antioxidant } \\
\text { Antiseptic, }\end{array}$ & Skin care products, \\
\hline Camellia sinensis & $\begin{array}{l}\text { Leaves, Flowers, } \\
\text { Roots, Seeds, } \\
\text { sprouts }\end{array}$ & Catechins & $\begin{array}{l}\text { Skin Protectant, } \\
\text { Antioxidant, }\end{array}$ & Oral care products, skin care products, \\
\hline Curcuma longa & $\begin{array}{l}\text { Leaves, } \\
\text { Rhizomes, Roots }\end{array}$ & Curcuminoids & $\begin{array}{l}\text { Skin protectant, } \\
\text { Antioxidant, } \\
\text { Antiinflamatory, } \\
\text { Perfuming }\end{array}$ & Eye care, skin care products, creams \\
\hline $\begin{array}{l}\text { Emblica } \\
\text { Officinalis }\end{array}$ & Fruits & $\begin{array}{l}\text { Vitamin C, phosphorus, } \\
\text { iron, calcium }\end{array}$ & $\begin{array}{l}\text { Anti-aging, Skin } \\
\text { Lightening, } \\
\text { Skin protectant, } \\
\text { Photoproctectant, } \\
\text { Antioxidant }\end{array}$ & Skin care products, creams \\
\hline Prunus dulcis & Oil & $\begin{array}{l}\text { Omega-3, } \\
\text { phenolic compounds }\end{array}$ & $\begin{array}{l}\text { Nourishing, softening, } \\
\text { cleansing, antioxidant }\end{array}$ & $\begin{array}{l}\text { Bath products, hair care products, } \\
\text { cleasing products }\end{array}$ \\
\hline $\begin{array}{c}\text { Rosa } \\
\text { Damascena, } \\
\text { Rosa centifolia }\end{array}$ & $\begin{array}{l}\text { Flowers, } \\
\text { Leaves, } \\
\text { fruits }\end{array}$ & $\begin{array}{l}\text { Beta-damascenone, } \\
\text { beta-damascone, } \\
\text { beta-ionone }\end{array}$ & Perfuming, tonic & $\begin{array}{l}\text { Bath products, skin care products, hair } \\
\text { care products, cleasing products }\end{array}$ \\
\hline Eucalyptus & $\begin{array}{l}\text { Leaves, } \\
\text { Oil }\end{array}$ & $\begin{array}{l}\alpha \text {-Pinene, } \\
\text { 1.8-Cineole }\end{array}$ & Anti-dandruff & Oral care, hair care products, skin care \\
\hline Castanea Sativa & $\begin{array}{l}\text { Barks, } \\
\text { Flowers, } \\
\text { Leaves, } \\
\text { seeds }\end{array}$ & $\begin{array}{l}\text { Rutin, hesperidin, } \\
\text { quercetin, apigenin, } \\
\text { morin, galangin, } \\
\text { kaempferol, isoquercitin }\end{array}$ & $\begin{array}{l}\text { Antioxidant } \\
\text { Antiaging }\end{array}$ & Skin care products \\
\hline Juglans regia $L$. & $\begin{array}{l}\text { Seeds, Flowers, } \\
\text { Leaves, }\end{array}$ & phenolic compounds & Antioxidant & Hair products \\
\hline Olea Europaea & $\begin{array}{l}\text { Barks, Flowers, } \\
\text { Fruits, Leaves, } \\
\text { seeds }\end{array}$ & Hydroxytyrosol, tyrosol & Antioxidant, Softening & Skin care products \\
\hline Vitis vinifera & $\begin{array}{l}\text { Seeds, Flowers, } \\
\text { Fruits, Leaves }\end{array}$ & Proanthocyanidins & $\begin{array}{l}\text { Antioxidant, } \\
\text { Skin protecting } \\
\text { Rejuvenating }\end{array}$ & Skin care products \\
\hline
\end{tabular}


for synthetic chemical compounds that used as excipient in cosmetic formulations such as emollients, surfactants and preservatives. Following examples can be given for plants which can be used instead of synthetic compounds: Instead of petrolatum and paraffinum liquidum, almond and sunflower oils and cocoa butter can be used. Aloe vera and Calendula can be used as emollient instead of cetyl/stearyl alcohol and stearalkonium chloride. As an alternative for Sodium Lauryl Sulphate, cocamide DEA and triethanolamine, Quillaja and Yucca saponins, Coconut and Palm Oil soap can be used as foaming agents. Hamamelis extract can be used for its astringent property as an alternative for ethyl alcohol. Generally used preservatives such as methylparaben, propylparaben, imidazolidinyl urea and phenoxyethanol have a variety of natural alternatives including Citrus seeds/peel extract, Eucalyptus, Tea tree oil, Green tea extract and ginger. A lot of plants used for coloring such as Beetroot powder (red), Carmine powder (purplish red), Paprika oleo-resin (orange red), Saffron (yellow-orange), carotenes (orange) and curcumin (yellow). ${ }^{1,2,20}$ Some of the plants used for cosmetic purposes and used product forms are presented in Table 1.

Activity of herbal cosmetics depends on not only the active chemical components of the plants used, but also many factors such as storage, packaging, microorganisms and pesticide residue; what time and which place the plants were collected and the environmental factors. To control these factors to provide the efficacy of the plants; standardization of herbal raw materials and final products are important. ${ }^{4,23}$ Herbal ingredients and cosmetics must be free from insects, pests, fungi, microorganism, insecticide and pesticide. They must be free from heavy metals; if heavy metals can't be removed, they must be within the permitted limits. They must show no abnormality in odor, color, taste and other signs of decomposition. Proper cleaning, sterilization, storage and handling conditions and compatible packaging materials for natural raw herbs or herbal ingredients must be provided. To preserve the stability of natural materials, exposure to light, air, moisture, heat and microorganisms must be kept under control. ${ }^{4}$ By taking into considerations these factors; stability studies must be designed in such a way that they include the tests for the physical, chemical, biological and microbiological features that are tended to change during storage and have effect on quality, safety, and efficacy of finished products. Tests should be conducted according to validated methods. ${ }^{24}$ Manufacturers must ensure the bioactivity of the natural components that herbal cosmetics contain, need to be retained through the shelf life. The quality control testing including organoleptic characteristics, $\mathrm{pH}$, viscosity and stability towards light must be carried out on the natural raw materials and the finished products. ${ }^{20}$

\section{NOVEL DELIVERY SYSTEMS}

The use of pharmaceutical delivery systems in cosmetics provides capabilities of enhancing cosmetic ingredients to deeper skin tissues, increasing duration of action, increasing stability, preventing incompatibility with other ingredients in the formulations or preventing the undesirable effects that may occur either locally or systemically (the undesirable effects faced with cosmetic products can be local; irritation, allergy, phototoxicity, photoallergy, systemic; damage to respiratory system, blood and organ systems, embryotoxic, teratogenic, estrogenic effects, mutagenic/photomutagenic and carcinogenic/ photocarcinogenic effects). ${ }^{15}$ To obtain above mentioned advantages searched and preferred delivery systems can be listed as; vesicular systems such as liposomes, niozomes, nanosomes, phytosomes, herbosomes, marinosomes, oleosomes, aquasomes, ultrasomes, photozomes, ethosomes, transferosomes, sphingosomes, colloidosomes; multilayered carriers; silicon carriers and matrices; emulsified systems such as microemulsions, multiple emulsions, nanoemulsion; microgel, nanogel, liquid crystals; particular systems such as microparticles, nanoparticles, solid lipid nanoparticles, nano-structured lipid carriers, microcapsules, nanocapsules, microspheres, nanocrystals and cyclodextrins. ${ }^{11,14,25-28}$ These delivery systems can be given in various pharmaceutical forms such as emulsion, gel, emulgel, bigel, etc. to obtain finished cosmetic product. As they are used in new generation advanced cosmetics, novel drug delivery systems are also used for herbal cosmetics. Developments of such formulations have also caused increase in patenting of cosmetic ingredients and formulations especially in the last decades. ${ }^{29}$ Among the novel delivery systems vesicular delivery systems (liposomes, nanosomes, phytosomes, herbosomes, marinosomes, oleosomes etc.), solid lipid nanoparticles, nanostructured lipid carriers and nanoemulsions are the most preferable systems. ${ }^{25,26}$ Advantages of such systems for herbal cosmetics can be listed as; improved stability, enhanced efficacy and decrease allergic potensial of some herbal substances. Liposomes are using in personal care products due to their benefits, such as sustained release, reduced toxicity, increased stability, and increased bioavailability. They are especially used in many anti-aging products to encapsulate vitamins, antioxidants, and natural botanical extract. ${ }^{10,12,14}$ Niosomes had been developed as an alternative controlled drug delivery systems to liposomes in 
order to overcome the problems associated with sterilization, large scale production and stability. The first niosome report came from a cosmetic company and then other cosmetic and drug industries started to use. Regarding nanoparticle efficiency there are many studies in cosmetic field to achieve the controlled release and targeting the cosmetic actives. Nylon nanoparticles are also used in make-up and skin care products to absorb oil and sunless tanning of the skin. Most of the nanocapsules are investigated for delivery of antioxidants and sunscreen agents. However, nanoparticle use in cosmetics is limited due to possible toxicity of the by-products. ${ }^{27}$ Lipid nanoparticles such as solid lipid nanoparticles and nanostructured lipid carriers have gained attention for dermal application of cosmetic active substances to achieve targeting and sustained release of active substances to the different layers of the skin. ${ }^{11,13}$ Above indicated delivery systems have been widely used in advanced cosmetic products defined as cosmeceuticals, dermocosmetics, functional cosmetics, quasi drugs which can also be herbal cosmetics. From this point of view the use of pharmaceutical delivery systems that can be used in herbal cosmetics are briefly presented as follows.

\section{Vesicular Delivery Systems}

Liposomes are phospholipidic vesicular systems including natural phospholipid lecithin which is obtained from soybean or egg. Both lipophilic and hydrophilic cosmetic actives are able to load liposomes but they are not allowed to reach systemic absorption and thus minimize undesirable effects. ${ }^{10}$ Liposomes have been used in skin care cosmetics including cosmetotextiles. Transfersomes are vesicular systems that presented better performance than liposomes in terms of suitability for wide range molecular weight cosmetic actives, compatibility, efficacy, permeability, ultraflexiblity and mechanical strength. Sphingosomes that are prepared with natural or synthetic sphingolipids have presented better stability than liposomes and offers targeting cosmetic actives to desired tissue, increase efficacy, stability and decrease toxicity of the cosmetic active substance. ${ }^{10,25,28}$ Phytosomes or Herbosomes have been prepared by polar botanical derivatives and generally plants including polar or water soluble molecules. They have offer advantages like; enhances the absorption of lipid insoluble polar phytoconstituents resulted as better efficacy, increased stability and decreased undesirable effects. ${ }^{10,28}$ Marinosomes are vesicular structures based on a natural marine lipid extract containing high ratio of polyunsaturated fatty acids which are metabolized by skin epidermal enzymes into anti-proliferative and anti-inflammatory metabo- lites, thus become an advantage for skin care products. Ethosomes are composed of phospholipids, ethanol in high concentration and water. Due to ethanol is an efficient permeation enhancer ethosomes are able to deliver active ingredients to the deep layers of the skin. Ethosomes are accepted as safe for cosmetic use. Colloidosomes are hollow elastic shells composed of colloidal particles having high encapsulation efficacy, permeability, mechanical strength and compatibility which are able to use for cosmetics. ${ }^{10,25}$ Niosomes are non-ionic surfactant based vesicle carriers that can be used to encapsulate cosmetic actives and enhances their permeation to the skin. Niosomes which are stable systems can improve stability of cosmetic actives and they are also less irritating than other colloidal vesicle carriers. Silicone vesicles and matrices consist of silicone elastomers and elastomer blends that can be used to entrap various cosmetic active ingredients. ${ }^{30}$ Silicone vesicles and matrices are able to use as cosmetic delivery systems in hair and skin care products. Physical associations of hair care actives with silicones have capability of improve conditioning, shine, reduce flyway and etc. The multi-walled delivery systems have provided longterm stability to cosmetic actives containing products for skin applications. They have nourishing and protecting property for the skin. They are effective on delivery of sunscreens and peptides. ${ }^{10,11}$

\section{Emulsion Delivery Systems}

Microemulsions are stable liquid dispersions of three to four components; water, oil, surfactant/s and co-surfactant/s. They used to delivery of cosmetic actives and decided due to good cutaneous tolerance and balanced lipophilic and hydrophilic property. Liquid crystals are the forms between conventional liquid and solid crystals. ${ }^{31}$ Liquid crystals allow lipophilic materials (vitamins etc.) incorporated into its matrix and protected them from thermal and photo degradation. In case of cosmetic actives delivery, emulsions containing liquid crystals have presented long lasting effect also provided stability of actives. Multiple emulsions generally can be $\mathrm{w} / \mathrm{o} / \mathrm{w}$ or $\mathrm{o} / \mathrm{w} / \mathrm{o}$ types in which globules of the dispersed phase encapsulate smaller droplets. Although w/o/w systems have been decided for cosmetics, their low stability have been restricted their use. ${ }^{32}$ Nanoemulsions are $\mathrm{o} / \mathrm{w}$ dispersions that having droplet diameter smaller than $100 \mathrm{~nm}$. Compared with microemulsions they have low stability but high penetration and hydration properties that is desired for cosmetics. Nanoemulsions allow transparent appearance and different rheological behaviors which have presented advantages for skin and hair care products. ${ }^{11,31}$ Pickering emulsions 
are o/w type emulsifier-free emulsions that are stabilized by solid particles (hydrophobically modified titanium dioxide, colloidal silica etc.) which adsorb onto the interface between the two phases. They are characterized by good skin tolerability and exhibit higher effectiveness in sunscreen products. ${ }^{33}$ Microgels are nanosized crosslinked particles that can form stable suspensions in water. They have presented different viscosity due to particle size of microgels and large surface area that allow better efficacy for cosmetic active ingredients. Nanogels are water soluble forms which consist of crosslinked, sub-micrometer sized particles made of hydrophilic polymers. They prefer in device mediated cosmetic applications such as derma-roller which enhances skin penetration of cosmetics. ${ }^{34}$

\section{Particulate Delivery Systems}

Microparticles are solid polymeric particles that are used in cosmetics to avoid incompatibility of substance, reduce odour of cosmetic actives and to protect active substances against oxidation or action by atmospheric moisture. Microcapsules are rather decided for encaplution of cosmetic ingredient or formula for cosmetotextile applications. Microsponges are highly cross-linked, porous, polymeric microspheres that can be divided into microporous-microbeads and microporous-macrobeads. They have presented advantages of sustained release and reduced irritation of cosmetic actives with an enhanced stability and efficacy. ${ }^{35}$ Nanoparticulates can be divided as nanospheres and nanocapsules that are both used in cosmetics. Solid lipid nanoparticles have presented advantages like enhanced skin hydration, protection against degradation, active penetration enhancement and sustained release of cosmetic actives. Nanostructured lipid carriers are nanoparticles in which the fluid lipid phase is embedded into the solid lipid matrix. Nanoparticulate systems show better stability than vesicular and emulsion systems. ${ }^{11,26,27}$ Cyclodextrins are cyclic oligosaccharides which are able to form inclusion complexes with cosmetic actives. Cyclodextrins are able to use for cosmetics and cosmetotextiles. ${ }^{36,37}$

\section{CONCLUSION}

Herbal cosmetics that are designed with novel drug delivery systems have presented some advantages such as providing high efficacy, enhanced stability, reduce undesirable effects and better aesthetic appearance of products. Besides these advantages novel delivery systems including herbal cosmetics have become more complicated in which quality requirements both during production, packaging and shelf life would become critical and thus need to be proved by long-term stability and dermatological safety tests.

\section{CONFLICT OF INTEREST}

The author declare no conflict of interest.

\section{REFERENCES}

1. Burlando B, Verotta L, Cornara L, Bottini-Massa E. Herbal Principles in Cosmetics: properties and mechanisms of action. New York: CRC Press; 2010. 56-97.

2. Plants in Cosmetics. Council of Europe Publishing, Strassbourg Cedex; 2001.

3. Alğın Yapar E, İnal Ö, Erdal S. Design and in vivo evaluation of emulgel formulations including green tea extract and rose oil. Acta Pharmaceutica 2013;63(4):531-44.

4. Masand S, Madan S, Balian S. K. Modern concept of storage and packaging of raw herbs used in Ayurveda. Int J Res Ayurveda Pharm. 2014; 5(2):242-5.

5. D'Amelio FS. Botanicals: a phytocosmetic desk reference. USA: CRC Press; 1999.

6. ISO 22716:2007 Cosmetics - Good Manufacturing Practices (GMP) Guidelines on Good Manufacturing Practices

7. ISO 16128-1:2016 Guidelines on technical definitions and criteria for natural and organic cosmetic ingredients and products - Part 1: Definitions for ingredients

8. ISO/DIS 16128-2.2 Cosmetics - Guidelines on technical definitions and criteria for natural \& organic cosmetic ingredients - Part 2: Criteria for ingredients and products.

9. Shrikumar S, Maheshwari U, Sughanti A, Ravi TK. WHO guidelines for herbal drug standardization, 2006.

10. Bugaj AM. Intradermal Delivery of Active Cosmeceutical Ingredients. In: Eds: Donnelly RF, Singh TRR. Novel Delivery Systems for Transdermal and Intradermal Drug Delivery. UK: John Wiley\&Sons, Ltd.; 2015. 209-30.

11. Gökçe EH, Algın Yapar E, Tuncay Tanrıverdi S, Özer Ö. Nanocarriers in Cosmetology. In: Ed: Grumezescu A. Nanobiomaterials in Galenic Formulations and Cosmetics, Applications of NanoBioMaterials. UK: Elsevier; 2016. 363-93.

12. Arora N, Agarwal S, Murthy RSR. Latest technology advances in cosmaceuticals. Int J Pharm Sci Drug Res. 2012;4(3):168-82.

13. Sharma B, Sharma A. Future prospect of nanotechnology in development of anti-ageing formulations. Int J Pharm Pharm Sci. 2012;4:57-66.

14. Patravale VB, Mandawgade SD. Novel cosmetic delivery systems: an application update. International Journal of Cosmetic Science 2008;30(1):19-33.

15. Alğın Yapar E. Cosmetovigilance and global approaches. Clin Exp Health Sci. 2016;6(2):93-7.

16. Singh SA. Phytopharmacovigilance In: Contemporary Phytomedicines. New York: CRC Press; 2017. 21-7.

17. Joshi LS, Pawar HA. Herbal cosmetics and cosmeceuticals: An overview. Natural Products Chemistry Research 2015;3(2):1-8.

18. Mishra AK, Mishra A, Chattopadhyay P. Herbal cosmeceuticals for photoprotection from ultraviolet B radiation: a review. Tropical Journal of Pharmaceutical Research 2011;10(3):351-60.

19. Gediya SK, Mistry RB, Patel UK, Blessy M, Jain HN. Herbal Plants: Used as a cosmetics. J Nat Prod Plant Resour. 2011;1(1):24-32.

20. Fathima A, Varma S, Jagannath $P$, Akash $M$. General review on herbal cosmetics. International Journal of Drug Formulation and Research 2011; 2(5):140-65.

21. Kapoor VP. Herbal cosmetics for skin and hair care. Natural Product Radiance 2005;4(4):306-14.

22. Ribeiro AS, Estanqueiro M, Oliveira MB, Lobo JMS. Main benefits and applicability of plant extracts in skin care products. Cosmetics 2015;2:48-65.

23. Pandey S, Seth A, Tiwari R, Singh S, Behl H. M, Singh S. Development and evaluation of antimicrobial herbal cosmetic preparation. African Journal of Pharmacy and Pharmacology 2014;8(20):514-28. 
24. Basar SN, Rani S, Zaman RA. Review on stability studies of unani formulations. Journal of Pharmaceutical and Scientific Innovation 2013;2(4):1-8.

25. Bansal S, Kashyap CP, Aggarwal G, Harikumar SL. A comparative review on vesicular drug delivery system and stability issues. Int J Res Pharm Chem. 2010;2:704-13.

26. Marcato PD, Durán N. New aspects of nanopharmaceutical delivery systems. Journal of Nanoscience and Nanotechnology 2008;8(5):2216-29.

27. Alğın Yapar E, İnal Ö. Nanomaterials and cosmetics. J Fac Pharm Istanbul 2012;42(1):71-98.

28. Saraf S. Applications of novel drug delivery system for herbal formulations. Fitoterapia 2010;81(7):680-9.

29. Alğın Yapar E. Intellectual property and patent in cosmetics. Marmara Pharmaceutical Journal 2017; 21(3):419-24.

30. Singh P, Ansari H, Dabre S. Niosomes-A novel tool for anti-ageing cosmeceuticals. Journal of Pharmaceutical Research 2016;6(10):6691-703.

31. Wiechers JW. Optimizing Skin Delivery of Active Ingredients From Emulsions: From Theory To Practice . In: Ed: Rosen MR. Delivery System Handbook for Personal Care and Cosmetic Product. UK: William Andrew, Inc.; 2005. 409-36.
32. Agrawal A, Kulkarni S, Sharma S. Recent advancements and applications of multiple emulsions. International Journal of Advances in Pharmaceutics 2016;4(6):94-103.

33. Marto J, Ascenso A, Simoes S, Almeida AJ, Ribeiro HM. Pickering emulsions: challenges and opportunities in topical delivery. Expert Opinion on Drug Delivery 2016;13(8):1093-107.

34. Xia LW, Xie R, Ju XJ, Wang W, Chen Q, Chu LY. Nano-structured smart hydrogels with rapid response and high elasticity. Nature Communications 2013;4:1-11.

35. Jadhav N, Patel V, Mungekar S, Bhamare G, Karpe M, Kadams V. Microsponge delivery system: an updated review, current status and future prospects. Journal of Scientific and Innovative Research 2013;2(6):1097-110.

36. Buschmann HJ, Schollmeyer E. Applications of cyclodextrins in cosmetic products: A review. Journal of Cosmetic Science 2002;53(3):185-91.

37. Singh MK, Varun VK, Behera BK. Cosmetotextiles: state of art. Fibres \& Textiles in Eastern Europe 2011;19(4):27-33.

Cite this article: Yapar EA. Herbal Cosmetics and Novel Drug Delivery Systems. Indian J of Pharmaceutical Education and Research. 2017;51(3)Suppl:S152-58. 